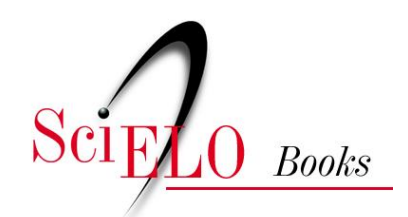

\title{
Seduepb
}

\section{O Querer-dizer de Jorge Amado no viés popular}

\author{
Maria Divanira de Lima Arcoverde
}

\section{SciELO Books / SciELO Livros / SciELO Libros}

ARCOVERDE, MDL. O Querer-dizer de Jorge Amado no viés popular. In: SWARNAKAR, S., FIGUEIREDO, ELL., and GERMANO, PG., orgs. Nova leitura crítica de Jorge Amado [online]. Campina Grande: EDUEPB, 2014, pp. 249-266. ISBN 978-85-7879-328-9. Available from SciELO Books $<$ http://books.scielo.org $>$.

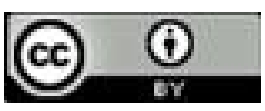

All the contents of this work, except where otherwise noted, is licensed under a Creative Commons Attribution $\underline{4.0 \text { International license. }}$

Todo o conteúdo deste trabalho, exceto quando houver ressalva, é publicado sob a licença Creative Commons Atribição 4.0.

Todo el contenido de esta obra, excepto donde se indique lo contrario, está bajo licencia de la licencia $\underline{\text { Creative }}$ Commons Reconocimento 4.0. 


\title{
O Querer-dizer de Jorge Amado no viés popular
}

\author{
Maria Divanira de Lima Arcoverde
}

\section{Introdução}

Jorge, mais do que Amado, se insurge neste colóquio, como "o ícone da literatura baiana" que ultrapassa os limites dos interstícios discursivos. Considerado um escritor atemporal, suas obras foram publicadas em cinquenta e cinco países e quarenta e nove idiomas e adaptada para outras mídias como televisão, cinema e teatro. Assim, seus personagens são transformados em parte indissociável da vida brasileira. Amante de expressões populares, o discurso de Jorge Amado torna-se inconfundível em suas obras literárias. Considerado um escritor coloquial por excelência, embora dominasse a variante culta, ele poderia dizer: "Meta a mão na cabaça quem quiser, não eu" (CASTILHO, 2008).

$\mathrm{Na}$ visão de Citoaian (2012), não se conhece na literatura brasileira obra social e vida mais densas do que teve Jorge Amado. Lutou a boa luta, não se omitiu, não tremeu, não foi o "coelho assustado" em que muitos intelectuais se transformaram diante da força. Despertou ódios. Teve livros apreendidos e queimados. Foi preso, perseguido, exilado, expulso da França e proibido (ele e seus livros) de entrar nos Estados Unidos. Mas, tudo isso, é um passado heroico que não pode ser anulado na base do "esqueçam o que escrevi”. 
Dentre os "perigos da literatura", no dizer de Todorov, está a permanência.

Suas obras relançadas a partir de 2008, pela Companhia das Letras, é um atestado de que mesmo tendo sido vítima de "um curto desdém da crítica", ele se manteve firme em seu projeto de cultura popular, pois "Quem engorda o gado é o olho do dono". Em seus propósitos de incorporação da linguagem popular, não dispensa as frases feitas, os provérbios, as gírias e os palavrões. Nas palavras do Prof. Eduardo de Assis Duarte - da Universidade Federal de Minas Gerais (UFMG), o coloquialismo em Jorge Amado é uma característica marcante das marcas literárias da opção militante do escritor baiano. Amado queria "escrever para o povo", seguindo o exemplo de escritores que, mundo afora, abraçaram a utopia socialista. Era um contador compulsivo de histórias e se a literatura para ele era vida, o seu "querer-dizer" também significava vida. Nesse processo de elaboração, Jorge Amado, na reflexão glissantina, "traça um 'rizoma com o mundo', irrigando a escrita na delicada busca de deciframento do real, tanto em campo estético, quanto nos campos histórico, político e ideológico" (GLISSANT, 2005, p.13).

Neste sentido, a dinamicidade da criação linguajeira de Amado, situada no universo da cultura, se dimensiona como um grande diálogo, cuja teia discursiva se desenvolve sob a base da materialidade linguística de discursos já-ditos. Isto provoca uma produção literária múltipla, levando em conta que a literatura é parte inalienável da cultura. 
Assim, o trabalho que ora apresentamos, se inscreve no Querer-dizer de Jorge Amado no viés popular, volvendo o nosso olhar para recortes de retomadas de discursos populares, especificamente, enunciados de curta extensão, introjetados como redes de significação na obra $A$ morte e a morte de Quincas Berro D’Água (2008).

\section{Os enunciados de curta extensão}

Refletir sobre a linguagem como objeto social, nos faz pensar sobre as formações da vida no cotidiano e nas interações verbais que se instauram entre interlocutores, sejam por meio de construções complexas ou as mais simples, como os provérbios, ou ditos populares, como são popularmente conhecidos, slogans, aforismos e tantas outras. Mergulhar nesses entrelaçados, cujos fios se sobrepõem e se enredam, como a fluir enunciativamente ou a se desalinhar no processo de nosso conhecimento, faz com que nos aproximemos dos vários sentidos que essas produções evocam.

$\mathrm{Na}$ concepção bakhtiniana, o enunciado concreto sempre une os participantes da situação comum como co-participantes que conhecem, entendem e avaliam a situação de maneira igual. O enunciado, consequentemente, depende de seu complemento real, material para um e o mesmo segmento da existência e dá a este material expressão ideológica e posterior desenvolvimento ideológicos comuns. (BAKHTIN; VOLOCHINOV, 1999, p.06).

Em Discurso na vida e na arte, Bakhtin afirma que 
um enunciado concreto como um todo significativo compreende duas partes: a) a parte percebida e realizada em palavras e b) a parte presumida. Nesse sentido, o enunciado pode ser comparado ao entimema, isto é, uma forma de silogismo em que uma das premissas não é expressa, mas presumida. No entanto, um enunciado concreto é um tipo especial de entimema, pois nas atividades da vida é um entimema social, objetivo. Ele é como uma "senha" conhecida apenas por aqueles que pertencem ao mesmo campo social. A característica distintiva do enunciado concreto consiste precisamente no fato de que eles estabelecem uma "miríade" de conexões com o contexto extraverbal da vida e, uma vez separados deste contexto, perdem quase toda sua significação.

Nestas esferas de realidade se intercalam os enunciados de curta extensão. Os enunciados de curta extensão são também maneira de usar a língua de modo conciso e pitoresco, cujo funcionamento atesta uma vertente processual que pode ser chamada de formações sociais discursivas. Essa relação dos acontecimentos discursivos teria como base mecanismos sócio-enunciativos e, mais amplamente, a abordagem da interação verbal, tendo em vista que o discurso verbal é um evento social. Ele não está autoencenado no sentido de alguma coisa, ou quantidade linguística abstrata, nem pode ser derivado psicologicamente da consciência subjetiva do falante tomada em isolamento. É a "alma social" do discurso que o torna belo ou feio e que lhe dá significado artístico. O enunciado concreto, como afirma Bakhtin, (e não a abstração linguística) nasce, 
vive e morre no processo da interação verbal/social entre os participantes da enunciação.

Os enunciados de curta extensão por serem considerados, como um elemento familiar, ao mesmo tempo, apresentam novidades e estranhamento porque rompem com o fio do discurso. Assim, são considerados como patrimônio comum, de um dizer conhecido por todos, não necessita, de comentários metalinguísticos ou mesmo de entoação especial para serem percebidos como um discurso diferenciado. Eles são também uma modalidade privilegiada de discurso do Outro, configurando o processo da alteridade.

Neste sentido, ao reenunciar o discurso do outro, o sujeito não está assumindo uma atitude passiva, mas interagindo no processo discursivo. Ouvir a voz do outro é caminhar para a constituição de uma subjetividade. A função das vozes narrativas amplia-se por meio de enunciados populares, estabelecendo um diálogo entre o "outrora e o agora". A alteridade então se vincula pela emergência do discurso do outro, aquele discurso que já foi dito, mas que se evidencia ao ser reeditado na reversibilidade do tempo e caracterizado por recorrências e analogias.

São essas recorrências que funcionam como dispositivos de uma memória discursiva. Os fatos do discurso, enquanto inscrição material em uma memória discursiva vêm restabelecer os implícitos (os pré-construídos, elementos citados e relatados, discursos transversos etc). $\mathrm{Na}$ visão de Pechêux (1999), a questão se dá em saber onde estão esses 
famosos implícitos, que estão "ausentes por sua presença". Eles estão disponíveis na memória discursiva como em fundo de gaveta, um registro do oculto? Esse efeito de opacidade que marca o momento em que os implícitos não são mais reconstruíveis é, provavelmente, o que compele a análise do discurso a se distanciar das evidências da proposição.

Dessa forma, a memória como interdiscurso é o saber discursivo que faz com que ao falarmos, nossas palavras façam sentido. Ela se constitui pelo já-dito que possibilita todo querer-dizer. Assim, Jorge Amado, como "sujeito assujeitado" é historicamente determinado pelo interdiscurso, pela memória do dizer, afetado pela língua e por algo que falou antes, em outro lugar. Palavras já-ditas, às vezes, esquecidas, ao longo do tempo e de nossas experiências de linguagem.

Os enunciados de curta extensão são considerados um interdiscurso, um tipo de expressão que, por representarem um valor social, podem funcionar em espaços discursivos distintos, ressaltando um traço relevante pelo fato de romperem na cadeia do significante, da qual o falante seria a principal fonte, o reconhecimento de que existe uma voz que falou antes dele. Ou seja, a voz de uma sabedoria anônima e popular, o que estabelece a ruptura, pois como sabemos, o usuário desses enunciados julga-se "o dono" desse dizer.

Dentre outras produções do cotidiano, os enunciados de curta extensão se inserem como caracterizados por uma constituição discursiva, marcada por um número reduzido de palavras que são mobilizadas na sua organização frasal,

\section{4}


mas com propriedades linguístico-discursivas próprias. Cada um desses pequenos enunciados mobiliza recursos estilísticos, temáticos e composicionais bastante específicos. Estes enunciados, na visão de Baronas (2011), se por um lado, precisam de um gênero discursivo que os aninhe, que lhes dê guarida, por outro, extrapolam todo e qualquer gênero. Eles acabam por adquirir autonomia discursiva em relação ao texto primeiro, organizando-se com sentido próprio. Estas expressões pertencem geralmente a um alhures discursivo, ou seja, ditos em outro lugar por um "sujeito universal" em que nem o contexto situacional nem o cotexto original são recuperáveis linguisticamente. Porém, como afirma Baronas (2011), sabemos que eles pertencem à sabedoria de uma certa comunidade.

Assim, esta linguagem cotidiana, usada nos mais diversificados horizontes sociais, em contextos e gêneros textuais variados, vai tecendo as inúmeras tramas que possibilitam o diálogo na abertura de fios que se entrelaçam na configuração dos discursos. Sem nome próprio, todas as espécies de linguagens dão origem a essas festas efêmeras que surgem, desaparecem e retornam. Por isto, a criação popular não tem nome; é coletiva; não tem autoria.

É nessa perspectiva que esses enunciados se constituem, fazendo parte de uma pluralidade cultural, que não pode ser hierarquicamente ordenada ou privilegiada, mas respeitada pela sua inviolável diversidade de modo de ser, de se manifestar culturalmente. A cultura passa a ser, então, uma força politicamente relevante, caracterizada por uma tendên- 
cia que tudo permeia, estreitamente aliada à vida social, cujo complexo de valores, costumes, práticas de vida e produções discursivas constituem um hibridismo geopolítico, cultural e étnico. Essas características sinalizam o entendimento da cultura popular como um saber coletivo, produzido por processos cognitivos e heterogêneos, em função dos quais os indivíduos definem as suas esferas de realidade.

Esses hibridismos consistem em intersecções entre culturas, e estabelece como propósito das ciências sociais situar-se entre as culturas nos lugares de cruzamento, fusões, conflitos e contradições. Jorge Amado insere em suas obras um intercâmbio cultural, ao conceber seus personagens, seus dizeres, tão verdadeiros quanto o querer-dizer do autor. No entanto, segundo Amorim (2001), na realidade, o autor não tem uma verdade acabada sobre seu personagem e ele entra em diálogo e se deixa alterar pela palavra do personagem. Para esta autora, é esta a condição primeira para o fenômeno do dialogismo bakbtiniano em relação à palavra do personagem, para que não se funda com o autor, "não lhe sirva de portavoz". A palavra de um personagem nunca é plena, acabada; ela se busca na palavra dos outros, que é quando faz sentido.

\section{0 querer-dizer e o já-dito}

Os discursos literários dialogizam socialmente a linguagem e são produzidos por fios ideológicos que os tecem por meio de relações dialógicas. Sabendo-se que a linguagem é dinâmica e que retoma os dispositivos teóricos, na perspectiva 
bakbtiniana, verificamos que a linguagem "é um produto da vida social que não é de nenhum modo congelado ou petrificado: ela está em perpétuo vir a ser e, em seu desenvolvimento, ela segue a evolução da vida social" (BAKHTIN, 1999, p. 55).

Sendo assim, os discursos são produzidos pelas filiações de sentidos constituídos em outros dizeres. O quererdizer não é propriedade particular. As palavras não são nossas. Elas significam pela História e pela língua. Para Orlandi (1999), há um "já-dito" que sustenta a possibilidade de todo dizer, na funcionalidade do discurso e suas relações com os sujeitos e a ideologia.

Bakhtin, como "fundador da discursividade", nos dá a certeza de que não há nenhuma escrita que não se coloque a palavra do Outro. Há sempre um sujeito que fala do outro lado (AMORIM, 2001, p.15). Derrida, citado por Amorim, também nos ensina que qualquer um pode declarar, sob juramento, que só tem uma língua e essa língua não é sua própria. É a língua do outro.

Desta forma, na esteira destes constructos, situamos o discurso de Jorge Amado como um fenômeno em que se entrecruzam todos os falares das linguagens sociais. Sua construção literária congrega uma linguagem socialmente típica e, em cada momento, histórica, assegurando um diálogo vivo que se constitui pelo "querer-dizer", pelo que "já foi dito" e pelo que tem a dizer.

É neste viés popular que o narrador de $A$ morte $e$ a morte de Quincas Berro D'Água (2008) vai tecendo os fios “da 
prosa inebriante de Jorge Amado" com todas as confusões que permanecem até hoje, "sem que se consiga distinguir o que é fato e o que é delírio etílico".

Assim é o mundo, povoado de céticos e negativistas, amarrados, como bois na canga, (grifo nosso) à ordem e à lei, aos procedimentos habituais, ao papel selado. [...] tentam apagar as horas intensamente vividas por Quincas Berro D’Dágua até sua partida, como declarou, em alto e bom som, (grifo nosso) aos amigos e outras pessoas presentes.

(AMADO, 2008, p.14)

Podemos observar que os enunciados em destaque são materialidades linguísticas de curta extensão, enquadrados como os provérbios, os aforismos, as máximas, dado o número reduzido de léxicos que mobilizam a sua organização. $\mathrm{Na}$ perspectiva discursiva possuem características próprias e são reconhecidos como o “já-dito” tendo em vista os aspectos composicionais que os especificam, constituindo um gênero textual distinto, facilmente reconhecível por fazerem parte do "Thesaurus" Cultural de um determinado grupo social.

Em outro fragmento da narrativa, destacamos as seguintes expressões:

Não tem cara de quem engana mari- 
do... Em compensação, devia ser um osso duro de roer... Santa mulher? Não acredito... (p.22). Não poderia mandá-lo plantar batatas... (p.26). E Vanda, com o rabo do olho, espiou o morto (p.28). Já Tio Eduardo explicava: Caro mesmo é o caixão. E os automóveis, se for acompanhamento grande. Uma fortuna. Não se pode nem morrer.

(AMADO, 2008, p. 22-31, grifo nosso)

Como vemos, Jorge Amado insere expressões populares de curta extensão em seu tecido literário, na certeza de que "o discurso do EU supõe uma dupla caricatura". Isto dá a entender que caracterizar o Outro é poder diferenciarse dele, mas ao não ter êxito nessa empreitada, representa, ao mesmo tempo, a "caricatura de si mesmo e de suas esperanças" (PONZIO, 2008, p.23). É, pois, no texto literário, como sistema simbólico de maior tradição, que encontramos a linguagem popular, assumindo um "entre-lugar", reinando como elemento híbrido (SANTIAGO, 2000). Para este autor, "a maior contribuição da América Latina para a cultura ocidental vem da destruição sistemática dos conceitos de unidade e de pureza" ( $p$ 16). Os conceitos de "pureza e unidade" perdem o contorno exato de seu significado; perdem seu peso esmagador, seu sinal de superioridade cultural, à medida que 
o trabalho dos latino-americanos se afirma e se mostra mais eficaz.

Amado situa-se, assim, neste "lugar aparentemente vazio", cumprindo um ritual que instaura o interdiscurso no campo literário, onde teríamos todos os dizeres “já-ditos” em uma estratificação de enunciados que representam o dizível.

Então Quincas Berro D’Água fazia seu solene juramento: reservara ao mar a honra de sua hora derradeira, (grifo nosso) de seu momento final. Não haviam de prendê-lo em sete palmos de terra (grifo nosso). Ah! Isso não!'(p. 49). (...) seus gritos cruzavam a ladeira de São Miguel, morriam no largo do Pelourinho, eram de cortar o coração. (AMADO, 2008, p.51, grifo nosso)

O saber discursivo de Amado foi se organizando ao longo da sua narrativa e produzindo dizeres que representam o eixo de sua constituição, ou seja, o interdiscurso. $\mathrm{Na}$ ótica de Orlandi (1999), as formulações feitas determinam o que dizemos. É preciso que o que foi dito por um sujeito específico e em horizonte social particular se apague na memória para que o "anonimato" possa fazer sentido em "minhas palavras".

Mostramos outro fragmento em que um enunciado de curta extensão muito conhecido é usado: "Tinha corrido 
a notícia de que Berro D’Água bateu as botas (grifo nosso). Tava tudo de luto. Quincas e os amigos riram"... (p.83).

Verificamos que o discurso dialogizado busca na memória discursiva um repertório humorístico por meio da linguagem conhecida por todos (BAKHTIN, 1999). A linguagem que provoca o riso nega o discurso de autoridade $\mathrm{e}$ afirma a relatividade das coisas. O discurso humorístico pertence à esfera particular da vida cotidiana e tem caráter lúdico e libertário. $\mathrm{O}$ enunciado bateu as botas, como unidade dialógica da língua foi aninhado no querer-dizer de Amado como um "já-dito", pertencendo a um alhures discursivo produzido originalmente por um sujeito universal. Este linguajar criado pela dinamicidade linguística é sociológico, dialógico e realizado pelo processo da interação verbal. É necessário esclarecer o que Baronas nos assegura:

Especificamente, as formas linguísticas de curta extensão congregam um conjunto de outros pequenos enunciados que, embora possuam características linguísticas semelhantes às dos provérbios, não se enquadram nesta categoria de formas linguístico-discursivas sobreasseveradas que se apresentam como elementos: a) relativamente breves, de estrutura pregnante no plano do significado e/ou do significante; b) em posição 
relevante no texto ou em uma passagem do texto de modo a lhe atribuir um estatuto de um condensado semântico, o produto de uma espécie de sedimentação da realização do discurso; c) (...) sua temática deve estar em relação com o intuito do gênero de discurso, do texto em questão; d) implica um tipo de "amplificação" da figura do enunciador, manifestada por um ethos apropriado.

(BARONAS, 2011, p.62)

\section{À Guisa de Conclusão}

Ao intentarmos analisar a linguagem popular na obra de Jorge Amado, era nosso interesse detectar a transposição de enunciados proverbiais no texto amadiano, tendo em vista os provérbios serem objeto de pesquisa em nossos estudos. No entanto, para nossa surpresa, a obra escolhida não propiciou este recorte. Direcionamos, então, nossa atenção para outros enunciados de curta extensão que, a exemplo dos provérbios, compõem um número significativo e inumerável de expressões populares, que povoam parte do repertório cultural das pessoas, usadas comumente no cotidiano. Ao registrar a incidência destes enunciados de curta extensão na obra A morte e a morte de Quincas Berro D'Água, poderíamos afirmar que Jorge Amado tinha o que Maingueneau (2001) chama de 
"vocação enunciativa", ou seja, o processo por meio do qual um sujeito se sente chamado a produzir literatura. Prova disso é o que Jorge Amado conta em seu livro autobiográfico $O$ Menino Grapiuna. Relata Amado que foi um professor de Língua Portuguesa, o Padre Luiz Gonzaga Cabral, o primeiro a dizer que ele seria escritor.

A linguagem de Amado, especificamente, o seu léxico precisa ser mais estudado. Esta linguagem chega a ser "erótica”, tátil... É mais que envolvente. Chega a ser sedutora. Para Castilho (2008), foi ao fundar sua linguagem no imaginário popular que Amado alcançou o seu projeto de literatura engajada.

Affonso Romano de Sant'Anna, no Posfácio da obra analisada, nos diz que Amado, fiel à oralidade como fonte de sabedoria popular, é um típico contador de histórias. Para ele, Jorge Amado constrói um "jogo de espelhos", um estilo "carnavalizador" como rito de inversão dos costumes, quando o avesso ocupa o lugar do certo. É a ficção virando realidade e o cotidiano e a fantasia se acoplando tanto quanto a vida e a morte. Acrescenta, ainda, que é "o êxito do arlequim sobre o pierrô, onde grotesco e sublime dialogam gostosamente. É a emergência do lado dionisíaco da existência" (p.101).

Vimos, assim, que Jorge Amado, mais que um romancista, mais que um escritor é aquele que encontrou "o entre-lugar" do discurso latino-americano, no dizer de Santiago (2000), para ancorar o seu querer-dizer, exercendo a potencialidade discursiva presente em todas as camadas 
sociais, em uso plural e dialógico. Interdiscursivamente, ele intercala em outro gênero as expressões de curta extensão, de autoria anônima e fortemente ligadas à tradição cultural, marcando desta forma, a alteridade que remete sempre a um Outro social.

O querer-dizer de Amado, marcado por um discurso de fácil reconhecimento, é vivificado pelo pragmatismo de seu uso no horizonte social, o que faz jus ao reconhecimento de suas obras estarem incluídas numa rede social que o destaca no cenário cultural e enunciativo do Brasil e do exterior.

\section{Referências}

AMADO, Jorge. A morte e a morte de Quincas Berro D’Água. São Paulo: Companhia das Letras, 2008.

AMORIM, Marília. O pesquisador e seu outro: Bakhtin nas ciências humanas. São Paulo: Musa Editora, 2001.

BAKHTIN, Michael; VOLOCHINOV, V. N. Marxismo e filosofia da linguagem. São Paulo: Hucitec, 1999.

BAKHTIN, Michael. A cultura popular na Idade Média e no renascimento. O Contexto de Francois Rabelais. São Paulo: Martins Fontes, 1997.

BARONAS, Roberto Leiser. Enunciados de curta extensão: 
gênero de discurso, aforização, Mídia e Política. In: Linguagem em (Dis)curso. Tubarão, SC: v.11, n. 1, p. 59-70, jan./ abr. 2011.

CASTILHO, Alceu Luis. O amante da expressão popular. In: Revista da Língua Portuguesa. Ano III. n.33. Jul/2008, p.23-32.

CITOAIAN, Ousarme. Jorge Amado. In: Universo paralelo. Ago/2012.

GLISSANT, Édouard. Introdução a uma poética da diversidade. Tradução de Enilce do Carmo A. Rocha. Juiz de Fora: Editora UFJF, 2005.

MAINGUENEAU, Dominique. O contexto da obra literária. São Paulo: Martins Fontes, 2001.

ORLANDI, Eni. Análise do discurso: princípios e procedimentos. São Paulo: Pontes, 2009.

PONZIO, Augusto. A Revolução Bakhtiniana. São Paulo: Contexto, 2008.

PECHÊUX, Michel. O papel da memória. In: ACHARD, Pierre.et al. Papel da memória. Tradução e Introdução de José Horta Nunes. Campinas, SP: Pontes, 1999. 
SANT'ANNA, Affonso Romano. Posfácio. In: AMADO, Jorge. A morte e a morte de Quincas Berro D’Água. São Paulo: Companhia das Letras, 2008.

SANTIAGO, Silviano. Uma literatura nos Trópicos: ensaios sobre dependência cultural. Rio de Janeiro: Rocco, 2000. 